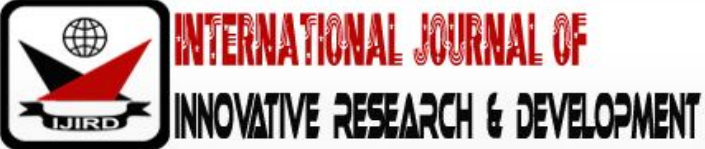

ISSN 2278 - 0211 (Online)

\section{Evaluation of High Voltage Transmission Line Towers Footing Earth Resistance under High Impulse Currents}

Johnson O. Aibangbee
Senior Lecturer, Department of Electrical/ Electronic and Computer Engineering,
Bells University of Technology, Ota, Nigeria
Steve O. Ikheloa
Lecturer, Electrical Technology Department,
National Institute of Construction Technology, Uromi, Nigeria

\begin{abstract}
:
In this paper, investigation of the performance of high transmission line towers footing earth resistances under high impulse currents was examined. The tower footings were properly earthed using the 3-point Fall-of-Potential and Multiple Earth Electrodes interconnected by both bare and insulated copper conductors to form ring electrode methods for the measurement of earth resistances. The earth resistances were simulated using CDEGS-HIFREQ software. Results show that the earth resistance of rod No.1 is $79.6 \Omega$; whereas that for rod No. 8 is $122 \Omega$. The differences were attributed to the lateral variation of the soil resistivity across the area occupied by the rods. Earth resistances measurements for a period of 13 months shown that the lowest values was $120 \Omega$ in June, 2017 and highest values of $165 \Omega$ in January same year for tower footing 1 ; Similarly, the

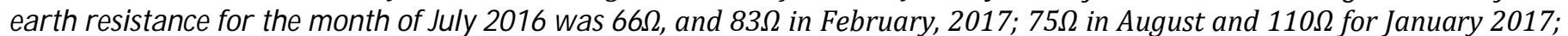
while the lowest and highest values were $60 \Omega$ and $90 \Omega$ in September 2016, and March, 2017 for tower footings 2, 3 and 4 over the periods. Earth resistance was lower in raining season during the months of June to November and higher in dry season during the months of December to May of the year. Using bare conductor ring, the earth resistance was $2.95 \Omega$. While the calculated value of the bare ring electrode with eight (8) rods at its periphery was $2.3 \Omega$. These values reduced considerably below the standard recommended value of $10 \Omega$. Using ring electrodes replicate current distribution in the soil around the tower base during lightning strikes.
\end{abstract}

Keywords: Earth electrodes, tower footing, earth resistance, fall-of-potential, ring electrode, soil resistivity

\section{Introduction}

Earthing systems of electricity substations and high voltage transmission lines is required to ensure electrical security of the power system and safety for persons working within or near the substation or in proximity of transmission towers to reduce damage to equipment while reducing disturbances to power system operations. Earthing systems are used to divert high currents to the earth. Lightning strikes can subject electrical power systems to transient currents and voltages of high magnitudes and fast rise-times which require dissipation to earth in a controlled manner [H. Griffiths and N. Pilling, 2004]. Lightning strikes to tall structures such as transmission towers can produce voltages so high that insulation can fail and electrical equipment can be destroyed. Such strikes produce an earth potential rise in the surrounding soil which can endanger persons who happened to be there at the time. Thus, high voltage transmission systems require lightning protection and insulation coordination schemes to protect personnel and power system equipment from danger and damages [Takehiko Takahashi and Taro Kawase,1991]. Thus, a properly designed earthing system capable of dissipating large currents safely to earth is required, regardless of the fault type. On high voltage transmission and distribution systems, such safety measures must minimize damage to electrical power system equipment and protect human beings from harm. The effects of lightning strikes on the performance of transmission lines are influenced by factors such as route location, shielding, insulation and tower footing resistance. When a lightning strike terminates on an overhead ground wire (OHGW), a high impulse current will flow to the ground, transmitted through the tower footing. Such currents produce a high impulse voltage on the tower structure and nearby ground surface with respect to a remote earth, and this can endanger the life of people close to the line or its towers. To reduce outage rates and exposure of human life to danger due to lightning strikes, the tower footing impedance must be kept to a minimum. In cases where the tower footing resistance is higher than the standards value of $10 \Omega$, additional measures including the use of a vertical or horizontal electrode can be considered to lower the resistances [Griffiths H. and Pilling, N. 2004;Takehiko T and Taro Kawase, 1991;Akihiro A, et al, 2012;IEEE Std 1313.2-1999]. In this paper, evaluation of tower footing earthing resistance under high impulse currents was carried out. 


\section{Description}

Transmission line towers footing earthing systems refers to metallic conductors of various geometrical shapes and sizes acting as electrodes and buried in the soil. The commonly used earthing electrodes are the vertical rod, horizontal electrode, ring electrode and earthing grid [Takehiko T and Taro Kawase,1991;Akihiro A, et al, 2012;IEEE Std 1313.2-1999]. According to IEEE Std. 1243-1997, the individual performance of each tower is important in determining the lightning performance of the transmission line. The overall performance of an entire transmission line is influenced by the individual performance of the towers rather than by the average performance of all the towers together [IEEE Working Group on Estimating the Lightning Performance of Transmission Lines, 1993].

According to IEEE 142 Green Book (2007), the resistance of a single earth rod electrode driven vertically, the electrode resistance can be calculated using the equation (1) if the soil resistivity is known. $\mathrm{R}=\frac{\rho}{2 \pi \mathrm{l}}\left[\operatorname{In}\left(\frac{8 \mathrm{~L}}{\mathrm{~d}}\right)-1\right]$

Where:R is the electrode resistance, $\Omega$; $\rho$ is the Soil resistivity, $\Omega-\mathrm{m} ; \mathrm{L}$ is the Length of electrode buried in soil, $\mathrm{m}$; andd is the outer diameter of earth rod, m.The IEEE Working group on modeling guidelines for fast front transients (1996); as well as James T. Whitehead,(1983), states that the current dependent tower footing resistance $\left(\mathrm{R}_{\mathrm{T}}\right)$ can be estimated usingequation 2;

$\mathrm{R}_{\mathrm{T}}=\frac{\mathrm{R}_{0}}{\sqrt{1+\frac{\mathrm{I}}{\mathrm{Ig}}}}$

Where $\mathrm{R}_{0}$ is the low frequency tower footing resistance in $(\Omega)$,Iis the lightning current through the footing resistance(A) andI $\mathrm{g}_{\mathrm{g}}$ is the soil ionization current and is given by equation 3;

$I_{g}=\frac{1}{2 \pi} \frac{E_{0} \rho}{R_{0}^{2}} A$

Where $\rho$ is the soil resistivity $(\Omega . \mathrm{m})$, andE $\mathrm{o}_{\mathrm{o}}$ is the soil ionization gradient $(\mathrm{kV} / \mathrm{m})$

When transmission line tower is erected in sand or rocky terrain of high soil resistivity, the tower footing requires supplemental electrodes to reduce the overall earth resistance. The vertical earth electrodes are the most common type of electrodes in earthing systems and usually the most economical to install. To reach a low earth resistance in high resistivity soil greater than $300 \Omega \mathrm{m}$, long vertical electrodes can be used and are driven to a few meters depth when soil conditions permit [Towne H. M.(1998), Bellaschi P. L.(1941),Liew A. C. and Darveniza M.(1994)]. In locations where the soil type is not homogeneous, rather, the resulting resistivity for a two-layer soil, the DC earth resistance of the earthing components for a single vertical earth electrode inserted into the upper layer of a soil consisting of a number of layers, the earth resistance is calculated[IEEE Std. 80-2000; BS 7430 (2011)] using equation (4).

$\mathrm{R}_{1}=\frac{\rho_{1}}{2 \pi \mathrm{l}}\left[\operatorname{In}\left(\frac{4 \mathrm{~L}}{\mathrm{r}}-1\right)+\sum_{\mathrm{n}=1}^{\infty} \frac{\mathrm{K}^{\mathrm{n}}}{2} \operatorname{In} \frac{\mathrm{nh} / \mathrm{L}+1}{\mathrm{nh} / \mathrm{L}-1}\right]$

Where $r$ is the radius of the electrode, $\mathrm{L}$ is the length, $\rho_{1}$ is the resistivity of the top layer of soil, $\mathrm{k}$ the reflection coefficient given by $\left(\rho_{2}-\rho_{1}\right) /\left(\rho_{2}+\rho_{1}\right), \rho_{2}$ is the resistivity of the bottom layer of soil, $\mathrm{n}$ is the number of earth electrodes and $\mathrm{h}$ is the depth of the upper soil layer.

For the ring electrode, equation (5) is used[Tagg G. F (2004)];

$R_{\text {ring }}=\frac{\rho_{1}}{2 \pi^{2} \mathrm{D}}\left(\operatorname{In} \frac{8 \mathrm{D}}{\mathrm{d}_{0}}+\operatorname{In} \frac{4 \mathrm{D}}{2 \mathrm{~h}_{0}}\right)$

The values of $\rho_{1}$ is taken as the resistivity of the top soil layer.Where $D$ is the ring diameter, ho its burial depth and do the diameter of the wire. According to Tagg G. F, (2004)the equivalent earth resistance of $n$ rods arranged in a circle can be calculated using equation (6)

$\mathrm{R}_{0}=\frac{\mathrm{R}_{1}}{\mathrm{n}}\left(1+0.5 \alpha+\alpha \sum_{\mathrm{s}=1}^{\mathrm{s}=(\mathrm{n} \mid 2-1)} \frac{1}{\sin \frac{\mathrm{s} \pi}{\mathrm{n}}}\right)$

Where $\alpha=r / R, R_{1}$ is the resistance of a single rod calculated from equation (4) with $r$ radius of the earth electrode $(r=8$ $\mathrm{mm}$ ) and $\mathrm{l}=2.4 \mathrm{~m}$, and $\mathrm{R}$ is the radius of the ring. For a ring electrode with 8 Rods at its periphery, the earth resistance is given in equation ( 7 ) as

$R_{c}=\frac{R_{\text {ring }} R_{o}-R_{m}^{2}}{R_{\text {ring }}+R_{0}-2 R_{m}}$

Where $\mathrm{R}_{\mathrm{m}}$ is the mutual resistance between the ring electrode and the rods given by

$\mathrm{R}_{\mathrm{m}}=\frac{\rho_{1}}{\pi^{2} \mathrm{D}} \mathrm{In}$

$\frac{4 \mathrm{D}}{\sqrt{\frac{2 \mathrm{lh}_{0}}{\mathrm{e}}}}$

The tower footings resistance can be computed using equation (4)for vertical earthing rods. In this case, it is assumed that each footing is represented by a cylinder with radius $r$ and length $L$ with a linear current source along its axis. The total 
earth resistance $\mathrm{R}_{\mathrm{T}}$, of rod electrodes in parallel can be obtained from equation(9) [Safe Engineering Services,(2006);Ahmed el Mghairbi (2012)];

For the tower base ( 4 footings in a square of side (s),

$\mathrm{R}_{\mathrm{T}}=\mathrm{R}_{1} \frac{1+2.707 \alpha}{4} \quad$ and $\alpha=\frac{\rho_{1}}{2 \pi \mathrm{Rs}}$

Where the equivalent radius $\mathrm{r}=27.4 \mathrm{~mm}, \mathrm{~S}$ is the spacing between electrodes, this should be less than the rod length ( $\mathrm{s}<\mathrm{L}$ );and $\mathrm{L}=3 \mathrm{~m} . \mathrm{R}_{1}$ is the earth resistance of the single tower footing determined using equation (4) where $\mathrm{r}$ in the equation replaced by the equivalent radius of the tower footing.

\section{Material and Methods}

Tower footing earthing resistance is the resistance offered by the metal parts of the tower and the ground resistance. When lightning hits the earth wire and travels through the tower to earth, the voltage developed at the cross arm of the tower is normally at zero potential will be so high as to produce a back flash-over thus transferring the surge that could have been discharged to ground, to the phase conductors and travelling on either side towards the power transformers, C.Bs, switches, bus bars and so on. It is therefore very important to protect against surge voltages damage of equipment and safety of personal working within or near the substation.

The towers footings were properly earthed using the 3-point Fall-of-Potential and Ring Earth Electrodes Methods. Data collected for the study was obtained through field work (site) areas presented in Table 1.The following listed equipment used for the tower footing Earthing Resistance measurement includes,

\begin{tabular}{|c|c|c|c|c|c|}
\hline 1 & Top layer resistivity $\rho_{1}$ & $200 \Omega \mathrm{m}$ & 8 & No of electrodes per Tower legn & 8 \\
\hline 2 & Bottom layer resistivity $\rho_{2}$ & $30 \Omega \mathrm{m}$ & 9 & No of Tower legs & 4 \\
\hline 3 & Depth & $9.0 \mathrm{~m}$ & 10 & Rod distance from tower & $100 \mathrm{~m}$ \\
\hline 4 & Electrode diameter D & $16 \mathrm{~mm}$ & 11 & Potential Rod distance & $61.8 \mathrm{~m}$ \\
\hline 5 & Electrode radius $r$ & $8 \mathrm{~mm}$ & 12 & Conductor CSA & $4.0 \mathrm{~mm}^{2}$ \\
\hline 6 & Electrode length l & $2.4 \mathrm{~m}$ & 13 & Bare conductor length & lots \\
\hline 7 & Ring radius & $30 \mathrm{~m}$ & 14 & Insulated conductor length & lots \\
\hline
\end{tabular}

Table 1: Collected data for Earth Resistance

- Megger DET 2/ 2 measuring instrument for DC earth resistance

- Number of electrodes,

- Sufficient Length of insulated and bare conductors,

- Measuring tape,

- Hammer (to drive electrodes),

- $\quad$ Megger DET 2/ 2 Earth Tester user's manual; and

- Simulations using Current Distribution Electromagnetic Grounding (CDEGS) Software analysis.

\subsection{Measurement of Earthing Resistances Using the 3-Pointfall of Potential Method}

The 3-point fall of Potential method shown in Figure 1 comprises of the earth electrode to be measured and two other electrically independent test electrodes labeled P (Potential) and C (Current). The test method is used to measure the ability of an earth ground system or an individual electrode to dissipate energy from a site. These test electrodes are electrically independent of the electrode to be measured. In this method, three electrodes were used. A known current is injected by the megger meter between the earth electrode under test e.g. tower base and then flows through the earth to the remote auxiliary electrode $\mathrm{C} 2$ placed far away from the electrode under test and returns to the meter; while the drop in voltage potential is measured between the inner earth electrode and the earth electrode.

Prior to measurement, the earth electrode to be measure must be disconnected from its connection at the site and connect the testing meter. to the earth electrode. Then, for the 3-pole Fall-of-Potential test, two earth electrodes are placed in the soil in a direct line sufficiently far away from the earth electrode. Using Ohm's Law (V = IR), the megger tester automatically calculates the resistance of the earth electrode and measured value recorded.

As shown in the Figure, the electrode P2 from the tower base is incrementally increased and a series of measurements taken. The plot of voltage against $\mathrm{P}$, contained a straight portion when the auxiliary electrode $\mathrm{C} 2$ was placed at sufficiently distance. Strictly, this distance is sufficiently large that the straight portion of the curve contains the point $\mathrm{P}$, where $\mathrm{P}=0.618 \mathrm{C}$, as this is the point on the curve which corresponds to the true earth resistance. To achieve the highest degree of accuracy when performing a 3-pole ground resistance test, it is essential that the probe is placed outside the sphere of influence of the tower base under test and the auxiliary earth; in order to avoid the effective areas of resistance being overlap and invalidate any measurements recorded. Here, the C2 probe was placed $100 \mathrm{~m}$ away from the tower base, and this distance was considered sufficient that the true earth resistance can be determined from measurements made with the potential electrode (P2) positioned at a distance $61.8 \mathrm{~m}$ from the tower base under consideration. The DC earth resistances of the individual rod electrodes were measured with the commercial DC earth resistance Megger DET 2/ 2 Instrument. This Instrument is capable of the user selecting test frequencies in the range of $105 \mathrm{~Hz}$ to $160 \mathrm{~Hz}$ with maximum test current of $50 \mathrm{ma}$. It is capable of maximum noise rejection of 40V peak to peak and $14 \mathrm{~V}$ rms at $50 / 60 \mathrm{~Hz}$ sinusoidal. 


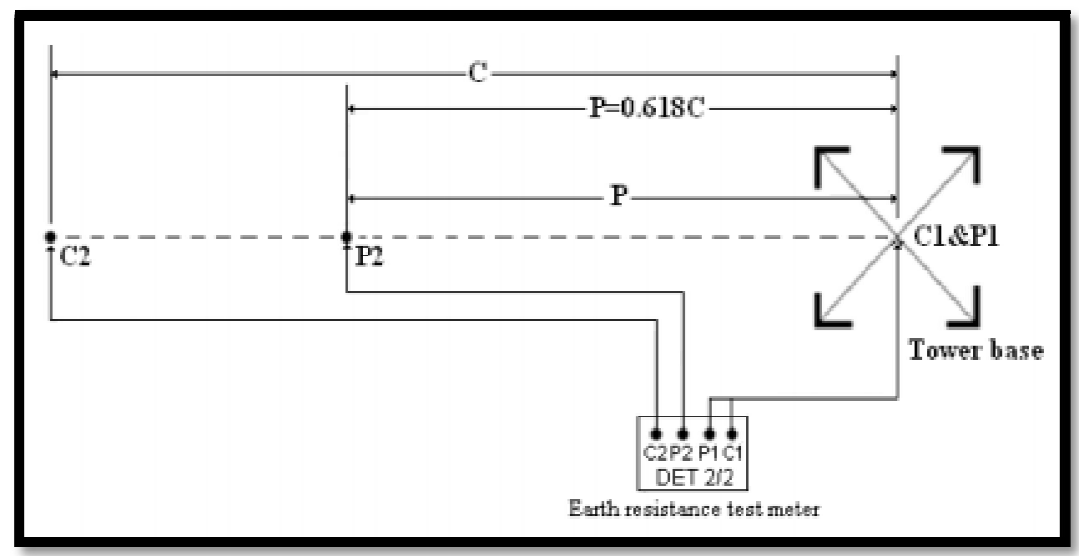

Figure 1: Three-Point Fall-of-Potential Method

\subsection{Experimental Test Setup Using Ring (Multiple) Earth Electrode Method}

The tower footing consists of four footings, arranged at the corners of a $7.25 \mathrm{~m} \mathrm{x} 7.25 \mathrm{~m}$ square; each having a depth of $3 \mathrm{~m}$. The construction detail of the footing is shown in Figure 2. In this design, more than one electrode were driven into the ground and connected in parallel to lower the resistance. A ring formation current return electrode surrounds the tower base and consists of eight (8) $16 \mathrm{~mm}$ diameter copper rods, each driven to a depth of $2.4 \mathrm{~m}$ in a circle of $30 \mathrm{~m}$ radius. For additional electrodes to be effective, the spacing of additional rods needs to be at least equal to the depth of the driven rod. Without proper spacing of the ground electrodes, their spheres of influence will intersect and the resistance will not be lowered. The rods were interconnected by sections of both bare and insulated copper conductors of $4.0 \mathrm{~mm}^{2}$, to form a ring electrode. These conductors were buried at a depth of $0.5 \mathrm{~m}$, and junction boxes located above the rods to allow for connection or disconnection of components and facilitate measurement of current and voltage at each position. A satellite image of a transmission line tower footing field test setup on site is shown in Figure 3.The figure highlights the positions of the four reinforced concrete tower footings forming the tower base.

Figure 4 shows the schematic diagram of the experimental setup. The resistances of individual eight (8) electrodes of the ring electrode rods were measured; the combinations of the electrodes connected with buried bare and insulated conductors were evaluated. The ring electrode type of horizontal earthing grid was used as peripheral earth conductors around structures so as to obtain even lower earth resistance; the horizontal earth grid was augmented with vertical rods which were inserted at the periphery of the earthing grid. The measurements were then compared with computed values. The measured and calculated values using equation (4) are tabulated in Table 2 . This arrangement with ring electrode replicate realistically the current distribution in the soil around the tower base during lightning strikes, compared with the more commonly-used single-rod return electrode arrangement. For lightning strikes on operational towers, the current in the ground distributes in all directions and returns to the system neutrals through infinite paths.

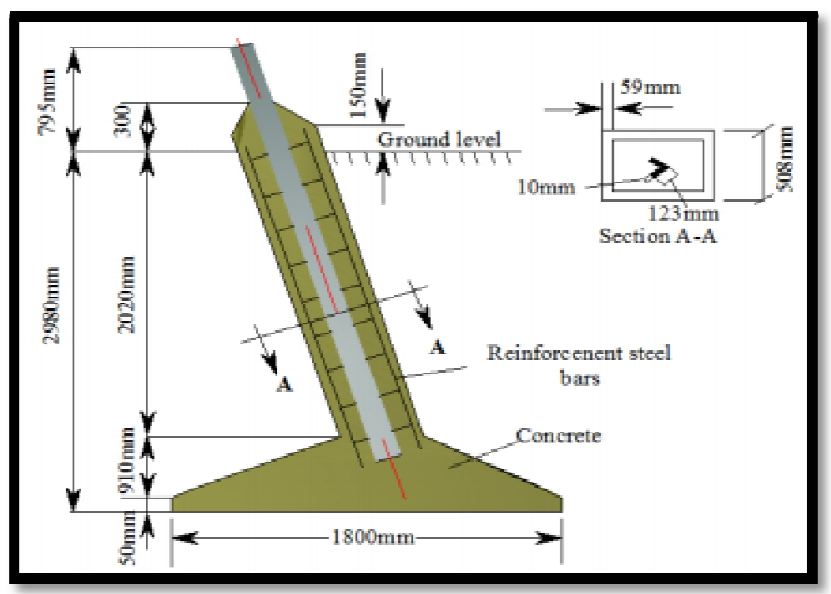

Figure 2: Construction Detail OFA Tower Footing Base 


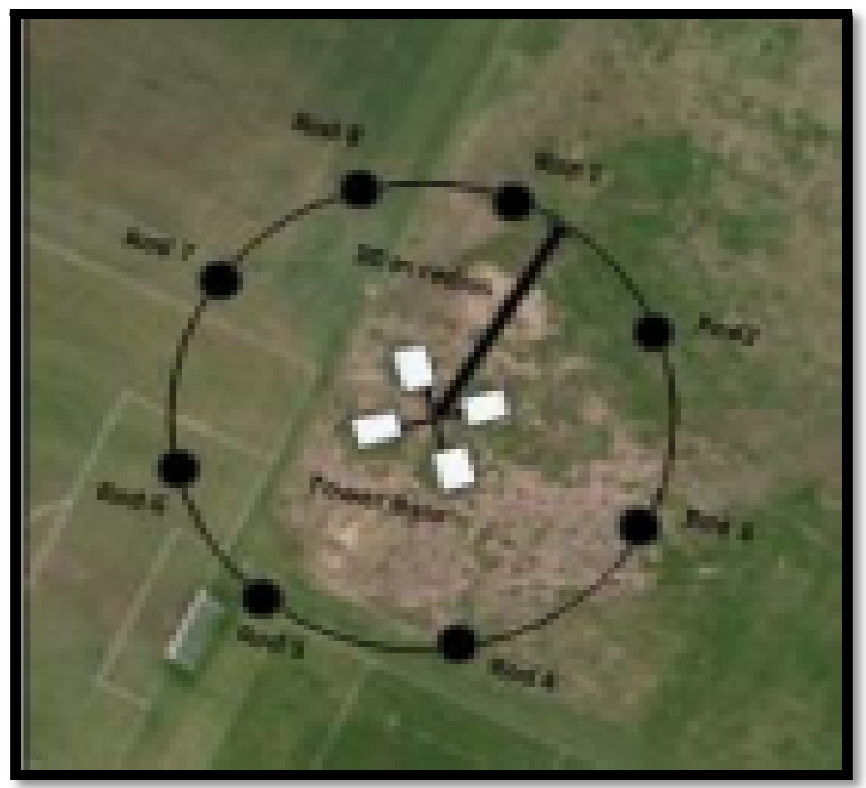

Figure 3: Satellite Image of Tower Base Test Site

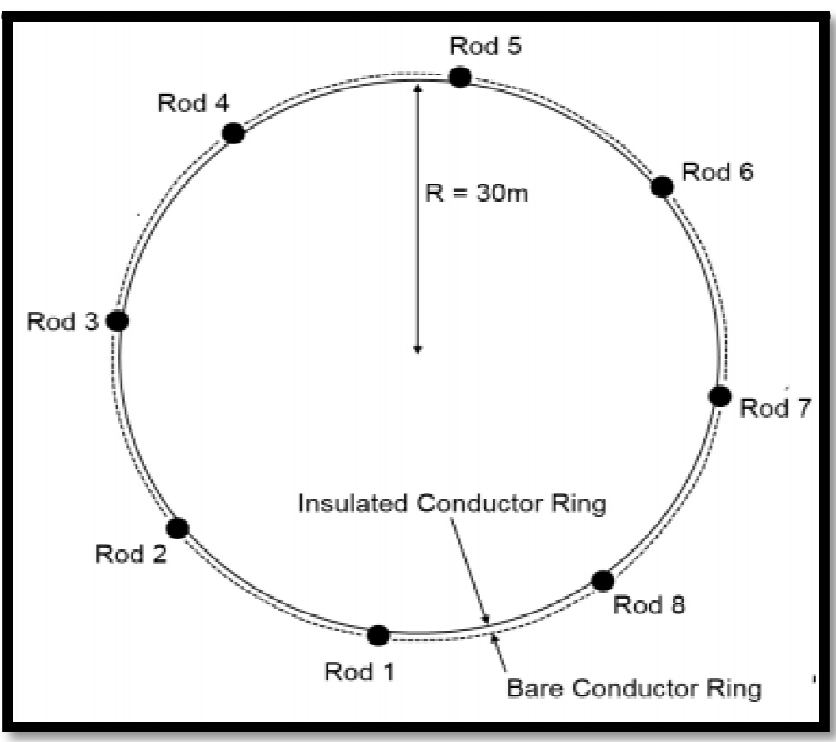

Figure 4: Test Setup of Ring Electrode of 8 Rods with Bare and Insulated Conductors

\begin{tabular}{|l|c|c|c|}
\hline \multirow{2}{*}{$\begin{array}{l}\text { Earth } \\
\text { Electrode }\end{array}$} & \multicolumn{2}{|l|}{$\begin{array}{l}\text { Earth Resistance } \\
(\Omega)\end{array}$} & $\begin{array}{l}\text { Percen- } \\
\text { tage } \\
\text { error } \\
(\%)\end{array}$ \\
\cline { 2 - 3 } & $\begin{array}{l}\text { Measu- } \\
\text { red }\end{array}$ & $\begin{array}{l}\text { Calcul } \\
\text { ated }\end{array}$ \\
\hline Rod No 1 & 79.6 & 94.0 & 18 \\
\hline Rod No 2 & 92.0 & 94.0 & 2.1 \\
\hline Rod No 3 & 88.7 & 94.0 & 5.9 \\
\hline Rod No 4 & 117 & 94.0 & 19.6 \\
\hline Rod No 5 & 88.7 & 94.0 & 6.0 \\
\hline Rod No 6 & 96.7 & 94.0 & 2.79 \\
\hline Rod No 7 & 105 & 94.0 & 10.4 \\
\hline Rod No 8 & 122 & 94.0 & 22.9 \\
\hline
\end{tabular}

Table 2: DCEarth Resistance of Vertical Electrodes

During measurement, the earth resistance tester was placed beside one of the eight (8) electrodes at each point, where the insulated and bare conductors were disconnected and / or connected to the earth rod to obtain different configurations of the ring electrode and measured values recorded as shown in table 2The geometrical test configuration 
was simulated using the high frequency (HIFREQ) module of the Current Distribution Electromagnetic Grounding (CDEGS) software.

In carrying out the simulation, all electrodes were modeled as cylindrical conductors with radii much smaller than length. A two-layer soil model was used where the upper layers soil resistivity is $200 \Omega \mathrm{m}$ with depth of $9 \mathrm{~m}$ and the bottom layer of soil resistivity is $30 \Omega \mathrm{m}$. The computed results in the Table 2 shows large differences between the measured and computed values of the DC earth resistance of the rods which is ascribed to the simple soil resistivity model.

\section{Analysis and Discussion}

Determining the tower earthing resistance, four separate partial measurements were made, one for each leg of the tower. The final result was determined by calculation as a parallel connection of the measured partial resistances.

The results tabulated in Table 2 where obtained using equation (4) to calculate the rod earth resistances. The calculated value of rod earth resistance is $94 \Omega$ which lies in the range between the minimum and maximum measured values. Results from table 2 also show that there are considerable differences in the magnitudes of measured earth resistances of the different rods. For instants, the earth resistance of rod No.1 is $79.6 \Omega$; whereas that for rod No. 8 is $122 \Omega$. The differences were attributed to the known lateral variation of the soil resistivity across the area occupied by the rods in the local area.

The DC earth resistance measurements were extended to the individual footings of the tower base and the tower base comprising the parallel connection of the footings. The results are shown in Table 3. As in the case of the rods, the DC earth resistance of the individual footing varies considerably, from $64.2 \Omega$ for footing No. 4 to $117.6 \Omega$ for footing No.1. Though the dimensions and construction of each footing are identical, the differences in values were due to the variation in local soil resistivity around the footings. The calculated results are also given in Table 3. The differences between calculated and measured results were attributed to the variation in local resistivity of the soil surrounding each tower footing.

\begin{tabular}{|c|c|c|c|c|}
\hline & \multicolumn{3}{|c|}{ DC resistance $(\Omega)$} & \\
\hline $\begin{array}{c}\text { Earth } \\
\text { Electrode }\end{array}$ & Measured & Calculated & $\begin{array}{l}\text { Difference B/W } \\
\text { Measured and } \\
\text { Calculated } \\
\text { values }\end{array}$ & $\begin{array}{l}\text { Percentage error } \\
\text { (\%)Measured }\end{array}$ \\
\hline Footing No 1 & 117.6 & 63 & 54.6 & 46.4 \\
\hline Footing No 2 & 67.2 & 63 & 4.2 & 6.2 \\
\hline Footing No 3 & 80.7 & 63 & 17.7 & 21.9 \\
\hline Footing No 4 & 64.2 & 63 & 1.2 & 18.6 \\
\hline Tower base & 20.9 & 21.9 & -1 & 4.7 \\
\hline
\end{tabular}

Table 3: DC Earth Resistance of Tower Footing

Table 4 also shows results of measured DC earth resistance for the rods interconnected by bare ring conductors with cross sectional area $4.0 \mathrm{~mm}^{2}$ and insulated ring conductors to form a ring electrode in various configurations using equation(6). The DC earth resistance of the rods connected in parallel by the insulated conductor is $13.4 \Omega$, as against $2.67 \Omega$, which is five times as high as when they are connected by bare sections of a conductor. In the case of the bare conductor ring, the earth resistance is $2.95 \Omega$ and when interconnected with the rods, a slight decrease in the resistance of $10 \%$ was observed. The calculated earth resistances of the ring electrode using equation (7) are tabulated in Table 4 . The DC resistance was calculated as $2.95 \Omega$ which is very close to the measured value. Similarly, the calculated earth resistances of the ring and the 8 electrodes in parallel connected with insulated conductoris $11.76 \Omega$ while the measured value is $13.4 \Omega$ resistances. Also, the calculated value of the bare ring electrode with eight (8) rods at its periphery was $2.3 \Omega$ compared with the measured value of $2.67 \Omega$. As can be seen, there is significant closeness in values between the calculated and measured values. For all configuration of the ring earth electrode, the results obtained were significantly close between the measured and calculated DC resistance values.

\begin{tabular}{|c|c|c|c|}
\hline \multirow{2}{*}{ Earth Electrode } & \multicolumn{2}{|c|}{ Dc Resistance $(\boldsymbol{\Omega}$} & \multirow{2}{*}{ Percentage Error (\%) } \\
\cline { 2 - 3 } & Measured & Calculated & \\
\hline Bare ring & 2.95 & 2.95 & 0 \\
\hline Bare ringwith 8 rods & 2.67 & 2.3 & 6.0 \\
\hline $\begin{array}{c}\text { 8 Rods in parallel } \\
\text { connectedwith insulated } \\
\text { conductor }\end{array}$ & 13.4 & 11.76 & 12.2 \\
\hline $\begin{array}{c}\text { Bare ring with 8rods and } \\
\text { insulated conductor }\end{array}$ & 2.66 & --- & 1.84 \\
\hline
\end{tabular}

Table 4: DC Earth Resistance of Ring Configurations

\subsection{Influence of Seasonal Variation on Earth Resistances}

The influence of seasonal variation on the measured earth resistance of the test earth electrodes was studied from June 2016 to June 2017; a period of 13 months. Earth resistance measurements were made using the fall-of-potential method for individual footing, the tower base, the eight electrodes in a circle connected by bare conductors and a single electrode (Rod1) as shown in Table 5, 6, and 7.The results are plotted in Figures 5, 6 and 7 respectively. Results shown 
that there are seasonal variations in soil resistivity which affects the resistance of earth electrodes and potentials developed in their close vicinity.

As shown in Figure 5, the earth resistance measurements for a period of 13 months shownthat the lowest values was $120 \Omega$ in June, 2017 and highest values of $165 \Omega$ in January same year for tower footing 1 ; Similarly, the earth resistance for the month of July 2016 was $66 \Omega$, and $83 \Omega$ in February and March, 2017; $75 \Omega$ in August and $110 \Omega$ for January and February 2017; while the lowest and highest values were $60 \Omega$ and $90 \Omega$ in September 2016, and March, 2017for tower footings 2, 3 and 4 respectively over the periods. The DC earth resistance varied over the year by $27 \% ; 25 \% ; 31.8 \%$ and $33.33 \%$ for tower footings 1, 2, 3 and 4 respectively. When the footings were connected in parallel to form the tower base, there was a variation of $22 \%$. The changes in DC earth resistance appear similar for all the electrodes and were due to variations in soil resistivity influenced by moisture content and temperature. The figure depicts that the resistance being lower in the raining season during the months of June to November and higher in dry season during the months of December to May of the year. Since one of the major factors in the resistance is the resistivity of the bulk of the soil surrounding the electrode is liable to variations with moisture content and temperature among other things, such as, effect of vegetation and bacteriological activity, which is highest in dry season. However, earth resistances for the month of June 2016, shown higher resistance than the corresponding month in 2017.

\begin{tabular}{|c|c|c|c|c|c|c|c|c|c|c|c|c|c|}
\hline \multirow{2}{*}{$\begin{array}{l}\text { Tower } \\
\text { Footing }\end{array}$} & \multicolumn{13}{|c|}{ Seasonal Variation of Earth Resistance (June 2016 to June 2017) } \\
\hline & June & July & Aug & Sept & Oct & Nov & Dec & Jan & Feb & March & April & May & June \\
\hline Foot 1 & 129 & 117 & 115 & 115 & 129 & 130 & 158 & 165 & $\begin{array}{c}16 \\
3\end{array}$ & 160 & 150 & 150 & 120 \\
\hline Foot 2 & 75 & 66 & 70 & 65 & 70 & 70 & 80 & 82 & 83 & 83 & 80 & 78 & 68 \\
\hline Foot 3 & 89 & 81 & 75 & 80 & 85 & 85 & 105 & 110 & $\begin{array}{c}11 \\
0\end{array}$ & 108 & 100 & 96 & 80 \\
\hline Foot 4 & 75 & 75 & 70 & 60 & 70 & 70 & 80 & 85 & 90 & 90 & 85 & 86 & 75 \\
\hline $\begin{array}{c}\text { Tower } \\
\text { Base }\end{array}$ & 25 & 25 & 21 & 20 & 20 & 21 & 25 & 27 & 27 & 27 & 25 & 28 & 21 \\
\hline
\end{tabular}

Table 5: Seasonal Variation of Earth Resistance Of Tower Base

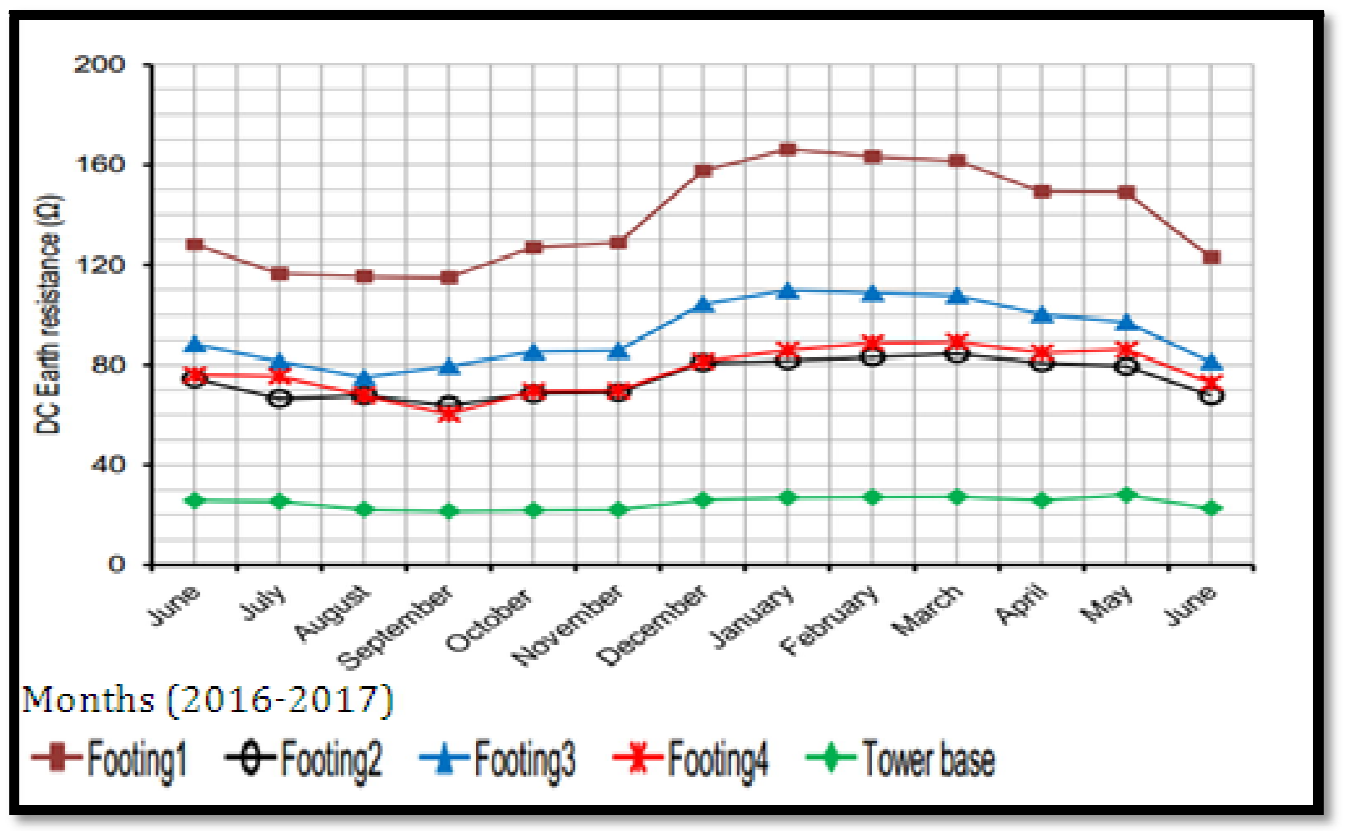

Figure 5: Seasonal Variation of Earth Resistance of Tower Footings and Base

In the case of the current return electrode, the rods interconnected by bare conductors buried at a shallow depth of $30 \mathrm{~cm}$ showed considerable variation in the DC resistance over the 13 months of the test. The maximum value was more than three times the minimum, as shown in Figure 6. This indicates that an earthing system buried in the soil layer near the surface is more exposed to seasonal variation than deeper earthing systems. For a single rod (No. 1) driven to a depth of $2.4 \mathrm{~m}$, there was very much less fluctuation in the DC earth resistance in Figure 7, and the average value over the 12 months period is $77 \%$; it shows very small variation in the measured DC resistance which is $10 \%$ on either side of the mean value over the period.

\begin{tabular}{|c|c|c|c|c|c|c|c|c|c|c|c|c|c|c|}
\hline Period & \multicolumn{5}{|c|}{ May - December 2016 } & \multicolumn{4}{|c|}{ January - June 2017 } \\
\hline Months & May & Jun & July & Aug. & Sept & Oct & Nov & Dec & Jan & Feb & Mar & Apr & May & Jun \\
\hline Resistances & 3.5 & 6.2 & 3.2 & 2.2 & 2.0 & 2.6 & 1.8 & 2.5 & 2.2 & 2.3 & 2.4 & 2.5 & 4.6 & 2.1 \\
\hline
\end{tabular}

Table 6: Eight Earth Electrodes in a Circle Connected by Bare Conductors 


\begin{tabular}{|c|c|c|c|c|c|c|c|c|c|c|c|c|}
\hline Periods & \multicolumn{4}{|c|}{ July - December 2016 } & \multicolumn{5}{|c|}{ January - June 2017 } \\
\hline Months & July & Aug & Sept & Oct & Nov & Dec & Jan & Feb & Mar & April & May & Jun \\
\hline Resistances & 85 & 82 & 73 & 69 & 76 & 80 & 72 & 74 & 77 & 77 & 82 & 75 \\
\hline
\end{tabular}

Table 7: Single Earth Electrode Rod 1

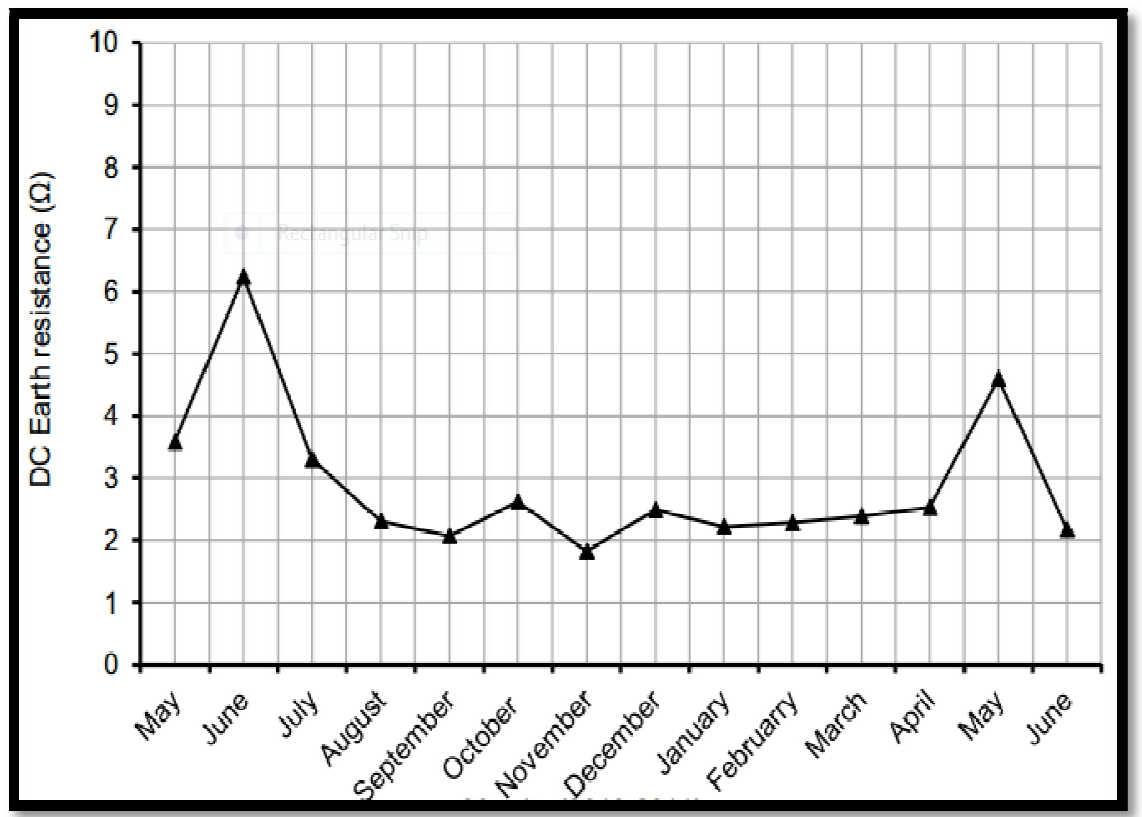

Figure 6: Seasonal Variation of DC Resistance

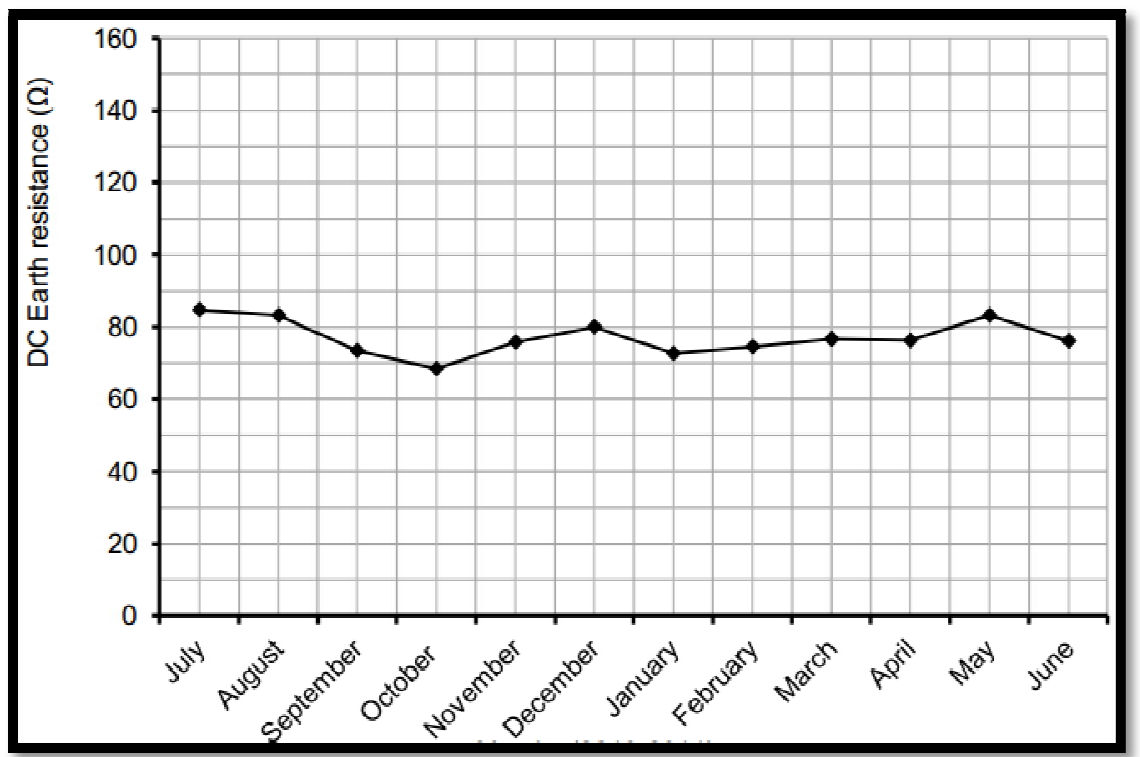

Figure 7: Seasonal Variation of DC Resistance for Rod No. 1 Bare Ring with All 8 Electrodes

\section{Conclusion}

The measurement of the earth resistance of electrodes is important for new installations to verify the design and, for existing installations, to ensure continued integrity. When enhancement of the earthing system of steel transmission lines is required, multiple earth rods and ring electrodes were employed.

In this paper, the earth resistance in the vicinity of a tower base under low voltage $\mathrm{AC}$ was investigated. The earth resistances were computer simulated using the high frequency (HIFREQ) module of the Current Distribution Electromagnetic Grounding (CDEGS) software. DC earth resistance measurements of earthing system components were presented based on the $61.8 \%$ rule fall of potential and the multiple earth electrodes with bare and insulated conductors connected in parallel to form a ring were presented. The influence of seasonal variation on the measured earth resistance of the test earth electrodes was studied from June 2016 to June 2017; a period of 13 months. Earth resistance measurements were made using the fall-of-potential method for individual footing, the tower base, the eight electrodes in a circle connected by bare conductors and a single electrode. The low magnitude impulse current injection was demonstrated experimentally that the surface potential around the tower base falls rapidly along the four diagonal profiles which can result in high step and touch voltages. The ground potential distribution into the concrete and the soil at 
different depths under impulse energization was also investigated experimentally. The use of a ring electrode allowed the test current to be more evenly distributed around the tower base, compared with the case of a single rod electrode.

\section{References}

i. Ahmed el Mghairbi (2012) "Assessment of Earthing Systems and Enhancement of their performance" School of Engineering, Cardiff University, Cardiff.

ii. Akihiro Ametani, Tomohiro Chikara, Hiroshi Morii, and Takashi Kubo (2012). "Impedance characteristics of grounding electrodes on earth surface," Electric Power Systems Research, vol. 85, pp. 38-43

iii. Bellaschi P. L. (1941) "Impulse and 60-cycle characteristics of driven grounds," AIEE Transactions, vol. 60, pp. 123-128.

iv. BS 7430: (2011). "Code of Practice for Protective Earthing of Electrical Installations," British Standards Institution. G.F. Tagg: (2004) "Earth Resistances," George Newnes Ltd, England.

v. Griffiths H. and Pilling N. 2004 "Earthing” Advance in High VoltageEngineering, A. Haddad and D. Warne, London: IET, pp. 349-413

vi. Harid N. Griffiths H. and Haddad A, (2011) "Effect of Ground Return Path on Impulse Characteristics of Earth Electrodes" 7th Asia-Pacific International Conference on Lightning (APL), pp. 686-689, China.

vii. IEEE 142 (Green Book) (2007), IEEE Recommended Practice for Grounding of Industrial and Commercial Power Systems

viii. IEEE 81(1983), IEEE Guide for Measuring Earth Resistivity, Ground Impedance, and Earth Surface Potentials of a Ground System

ix. IEEE Fast Front Transient Task Force, (1996) "Modeling guidelines for fast front transients," IEEE Transactions on Power Delivery, vol. 11, No. 1, pp. 493-506.

x. IEEE Guide for Improving the Lightning Performance of Transmission Lines, IEEE Std 1243-1997.

xi. IEEE Guide for the Application of Insulation Coordination, IEEE Std 1313.2-1999.

xii. IEEE Std. 80 (2000) "Guide for Safety in Substation Grounding" The Institute of Electrical and Electronic Engineers, New York.

xiii. James T. Whitehead, (1983) "Lightning performance of 500-kV and 161-kV transmission lines," IEEE Transaction on Power Apparatus and Systems, vol. PAS-102, No. 3, pp. 752-768.

xiv. Liew A. C. and Darveniza M. (1974). “Dynamic model of impulse characteristics of concentrated earths," Proc IEE, vol. 121, No. 2, pp. 123-135.

xv. Megger DET2/ 2. Auto earth tester specification.AVO.

xvi. Safe Engineering Services, (2006) "Current distribution electromagnetic grounding analysis software (CDEGS)," Canada,

xvii. Swapnil. G. Shah and Nitin. R. Bhasme (2014) “Design of Earthing System for HV/ EHV ACSubstation”International Journal of Advances in Engineering \& Technology, India.

xviii. Takehiko Takahashi and Taro Kawase, (1991) "Calculation of earth resistance for a deep driven rod in a multilayer earth structure," IEEE Transactions on Power De1ivery, vol. 6, No. 2, pp. 608-614,

xix. Towne H. M. (1998). "Impulse characteristics of driven grounds," General Electric Review, vol. 31, No.11, pp.605609,

xx. Working Group on Estimating the Lightning Performance of Transmission Lines, (1993), "IEEE Working group report estimating lightning performance of transmission lines II-updates to analytical models", IEEE Transaction on Power Delivery, vol. 8, No. 3, pp. 1254 - 1267. 